\title{
Effect of Wind and Seismic Forces on Intze Type Water Tank for Different Zones as per Indian Standards
}

\author{
${ }^{\text {*1} D r}$. P. D. Hiwase, ${ }^{2}$ Dr. P. P. Dahale, ${ }^{3}$ Dr. A. A. Mehta, ${ }^{4}$ Er. Bhavesh Rajesh Sahni \\ ${ }^{1,2,3}$ Civil Engineering Department, Shri Ramdeobaba College of Engineering and Management, Nagpur \\ ${ }^{4}$ Arun Uttarwar and Associate Structural Designer, Nagpur \\ Email: ${ }^{1}$ prashant.hiwase@gmail.com, ${ }^{2}$ dahale.p.prasad@gmail.com, ${ }^{3}$ mehtaaa@rknec.edu, \\ ${ }^{4}$ bhavesh.sahni26@gmail.com
}

Received: 22nd October 2019, Accepted: 20th November 2019, Published: 31st December 2019

\begin{abstract}
Water tank structures are of high importance as they act as a storage unit for basic necessity. During disasters it is very important that these do not fail and serve the purpose they are intended for. So it becomes very necessary that water tank is analyzed and designed for seismic and wind forces so that these structures do not fail under effect of Earthquake and Wind. Our study deals with seismic wind analysis w.r.t., Base shear, Seismic Zone, Response spectrum, Time Period of Intze water tank for different zones as per Indian Standards. Analysis has been carried out using Staad pro software.
\end{abstract}

\section{Keywords}

Intze Water Tank, Base Shear, Seismic Zone, Response Spectrum, Time Period

\section{Introduction}

Water tanks are used to store water. All the criteria like shape and properties like slab width and stresses all depends on the capacity and shape of Water tank. If we see generally Intz shape is preferred over other shapes is because of the uniformity in stresses in all directions. INTZ type water tank is one such water tank which has circular shape with a spherical top and conical slab with spherical dome at the bottom. The specialty of Intze water tank is that, the inward forces coming from the conical slab counteract the outward forces coming from the bottom dome which result less stress on the bottom slab of the water tank. Due to lesser stresses, the pressure on the base slab decreases and thus reduces in the quantity of members.[9]

\section{Need of Research}

Intze type water tank are generally designed for self-weight and gravity loads but is becomes necessary to study to behaviour of water retaining structure under the action of both seismic and wind loads so that these structures perform better under if they are built in seismic prone zones or areas with high wind capacity.[1]

\section{Methodology}

A basic model of Intze Water Tank has been modelled. All the components of the Intz Water tank have been modelled in Staad pro. Response Spectrum has also been applied in addition to the static analysis.

\section{Components of Intze Water Tank[2]}

Following components are present in Intz water tank and have been modelled in Staad pro.

1)Foundations: These are used the transfer the load from columns to Soil. Fixed support has been modelled in Staad pro to transfer the load to soil.

2) Columns: These are designed for the total load transferred to them. The columns will be braced at different levels as per design.[8]

3) Braces: They are tied at equal intervals. These are used to reduce the buckling of the columns. [7]

4) Bottom Spherical Dome: The floor may be circular or domed. This slab is supported on the ring girder and is modelled using plates.

5) Conical Slab: This will be designed for hoop tension due to water pressure. The slab will also be designed as a slab spanning between the ring beam at top and the ring girder at bottom and is modelled as plates.

6) Bottom Ring Beam: This ring beam is provided to resist the horizontal component of the reaction of the conical wall on the cylindrical wall. The ring beam will be designed for the induced hoop tension.

7) Cylindrical Wall: This has to be designed for hoop tension caused due to horizontal water pressure. 8) Top Ring Beam: The ring beam is necessary to resist the horizontal component of the thrust of the dome. The ring beam will be designed for the hoop tension induced. 
9) Top Dome: The rise is usually $1 / 5$ th of the diameter Load Properties [3-6]

The values of the loads assigned and material properties have been predefined in Staad pro. Following properties and loads have been assigned in the models.

Grade of Concrete: M-30

Grade of Steel: fe-500

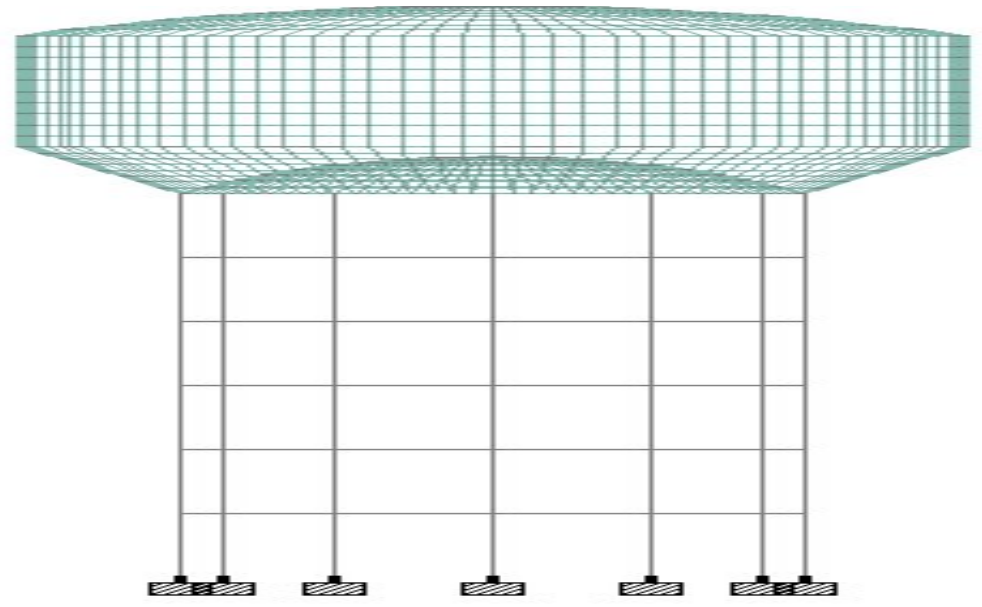

Fig 1: Model of Intz Water Tank

\begin{tabular}{|c|l|l|}
\hline Sr.no. & \multicolumn{1}{|c|}{ Details } & \multicolumn{1}{|c|}{ Value } \\
\hline 1 & $\begin{array}{l}\text { Dead Load: Floor Finish-1.0 kN/m²; } \\
\text { Self-Weight }\end{array}$ & $1.0 \mathrm{kN} / \mathrm{m}^{2}$ \\
\hline 2 & $\begin{array}{l}\text { Live Load as per water pressure and } \\
0.75 \mathrm{kN} / \mathrm{m} 2 \text { for roof }\end{array}$ & Type II \\
\hline 3 & Type Of Soil & 1.5 \\
\hline 4 & Importance Factor & 5 \\
\hline 5 & Response Reduction Factor & II,III,IV\&V \\
\hline 6 & Zone & \\
\hline
\end{tabular}

Table 1: Details of Data Used in Modelling

Wind Pressure is applied on all the elements as per IS 875 Part 3 considering basic wind speed as 44 $\mathrm{m} / \mathrm{s}$ and pressure calculated as per topography. [3-6]

\section{Intze Tank Properties}

Following are the properties of different elements considered during the analysis.

1. Column - $600 \mathrm{~mm}$ circular and 12 numbers.

2. Bracing- $300 \times 350 \mathrm{~mm}$

3. Bottom Ring beam $-600 \times 950 \mathrm{~mm}$

4. Bottom Dome Slab $-150 \mathrm{~mm}$ increasing to $250 \mathrm{~mm}$ at edges.

5. Conical Slab $-300 \mathrm{~mm}$

6. Cylindrical Wall-250 $\mathrm{mm}$

7. Top Ring Beam- 950 x $650 \mathrm{~mm}$

8. Top Dome $-125 \mathrm{~mm}$

\section{Results and Discussions}

This paper investigates the behavior of an Intz type ESR for seismic and wind conditions.

The loads applied on the tank are depicted below. 

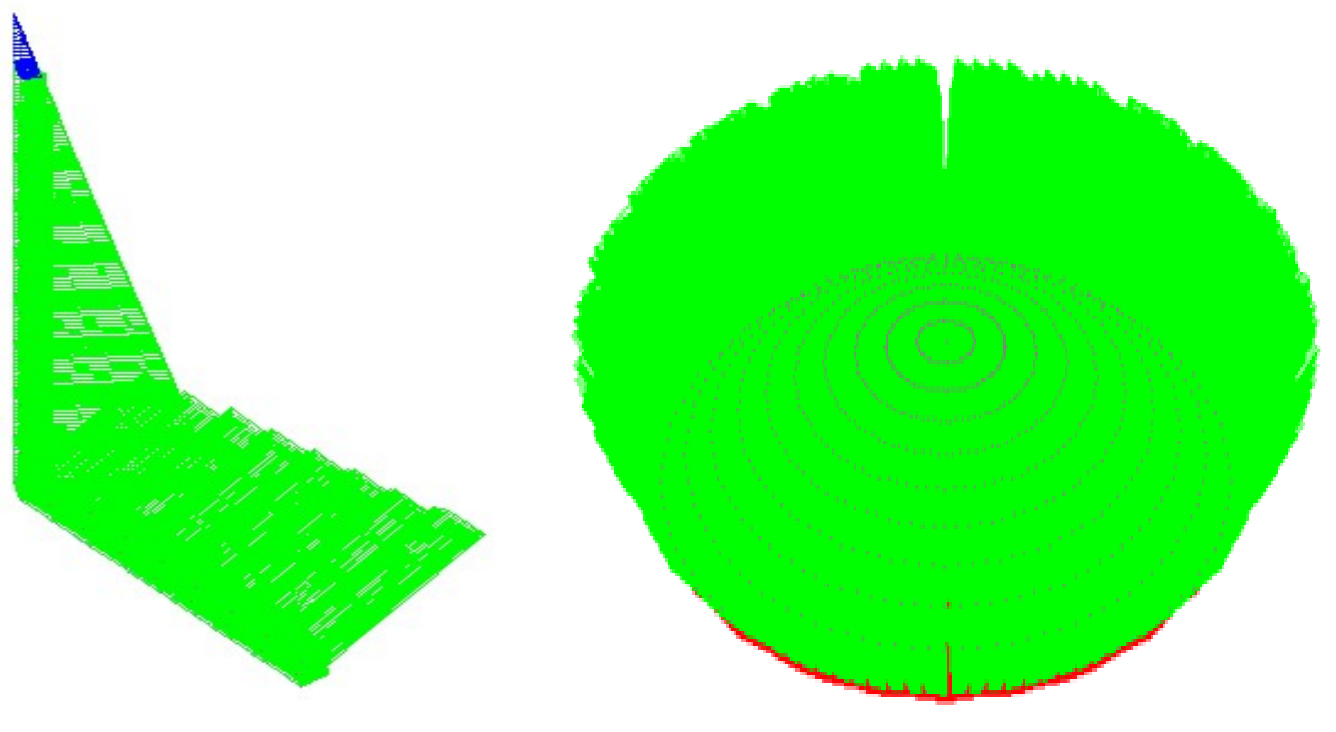

Fig 2: Water Pressure applied on Conical Slab and Wall

Fig 3: Water Pressure applied on Bottom Dome

Here figure 2 shows how load is applied on the walls; the loads are calculated as hydraulic pressure which is calculated by multiplying height with the density of water. The loads are constantly varying with height.

Here figure 3 shows the application of water pressure on the bottom done and load is varying as per the height of water.

\section{Comparison of Bending Moment of various Zones}

Let's compare the bending moment of structure for different zones for maximum loading. Following are the different Bending moment of Intz type water tank for seismic zone 2, seismic zone 3and seismic zone 5 as shown in figure number 5 , figure number 6 and figure number 7 . 


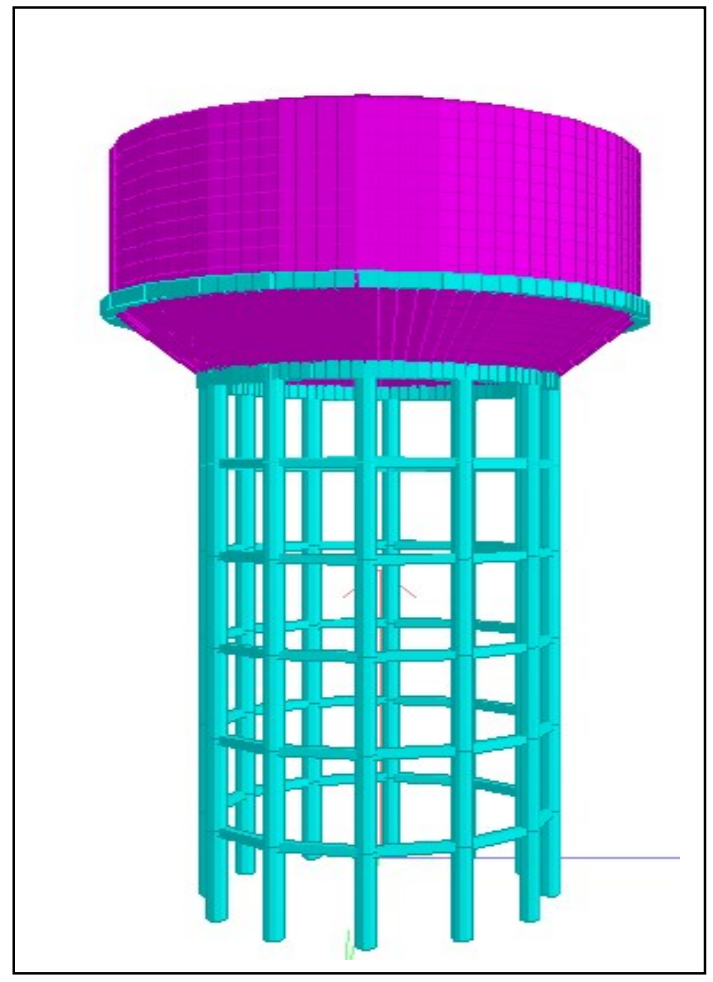

Fig 4: Rendered View of Model

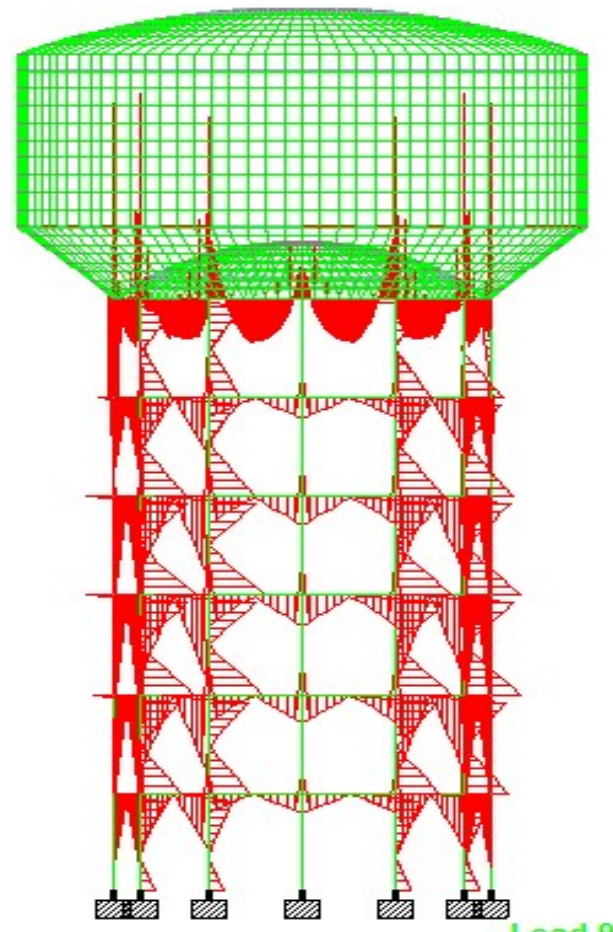

Fig 6: Value of Bending Zone 5

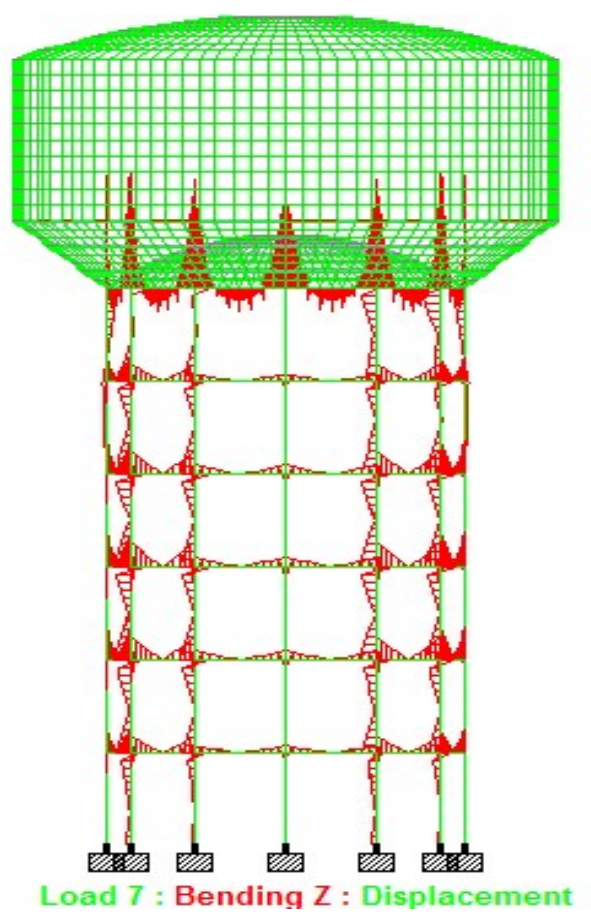

Fig 5: Value of Bending Zone 2

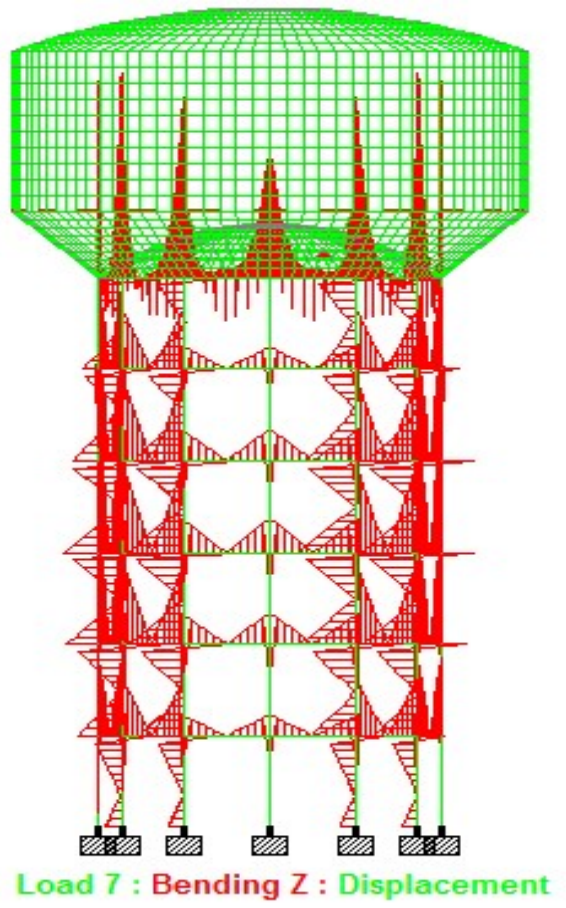

Fig 7: Value of Bending Zone 6

\section{Conclusion}

- The value of Base Shear increases with increase in Seismic Zone.

- Similarly the value of moments also increases as we go up the seismic zones. 
- Apply Response spectrum gives same result as static analysis because of the circular shape.

- The time period given by staad pro matches exactly with calculated by empirical formula given in IS $1893-2016$.

- The Seismic forces are dominant over the wind forces because of the topography considered by while applying wind loads.

- If we change the topographical conditions then wind forces can be a driving factor.

- However when wind load is governing factor then the value of moment for Tank Empty condition is maximum.

\section{References}

1. Ankit Sachdeva, Gourav Sachdeva and P. Hiwase, "Seismic response of Column with different shapes" International Journal of Emerging Trend in Engineering and Basic Sciences (IJEEBS) ISSN (Online) 2349-6967 Volume 4, Issue 2 (March-April 2017), PP.036-041

2. IITK-GSDMA guidelines for seismic design of liquid storage tanks", Gujarat State Disaster Management Authority, October 2007

3. IS code 3370 (Part-II)-2009 Code of practice for Concrete Structures for the Storage of Liquids.

4. IS code 1893 (Part-II)-2014 Criteria for Earthquake Resistant Design of Structures. Liquid Retaining Tanks.

5. IS code -1893-2016, "Criteria for Earthquake Resistant Design of Structures - Part I, General provisions and buildings Sixth Revision)".Bureau of Indian Standards, New Delhi.

6. IS code 3370 (Part-I)-2009 Code of practice for Concrete Structures for the Storage of Liquids.

7. Issar Kapadia, Nilesh Dholiya, Purav Patel and Prof. Nikunj patel "Parametric study of RCC staging (support structure) for overhead water tanks as per IS: 3370", IJAERD, Volume 4, Issue 1, January -2017.

8. Luis A. Godoy, -Damage Due to Buckling in Above Ground Storage Tankll, University of Puerto Rico, Mayaguez, PR 00681- 9041, Puerto Rico

9. Sohail Khan, P. Hiwase and P Pachpor "Analysis and Design of Underground Retaining Wall by Using Beam and Column As Buttresses" International Journal for Science and Advance Research in Technology (IJSART), ISSN [ONLINE]: 2395-1052, Volume 3,Issue 5 , May2017, Pages 936-940 